How to cite this article:

Katuk, N., Ku-Mahamud, K. R., Zakaria, N. H. \& Jabbar, A. M. (2020). A scientometric analysis of the emerging topics in general computer science. Journal of Information and Communication Technology, 19(4), 583-622. https://doi.org/10.32890/ jict2020.19.4.6

\title{
A SCIENTOMETRIC ANALYSIS OF THE EMERGING TOPICS IN GENERAL COMPUTER SCIENCE
}

\author{
${ }^{1}$ Norliza Katuk, ${ }^{1}$ Ku Ruhana Ku-Mahamud, \\ ${ }^{1}$ Nur Haryani Zakaria \& ${ }^{1,2}$ Ayad Mohammed Jabbar \\ ${ }^{1}$ School of Computing, Universiti Utara Malaysia, Malaysia \\ ${ }^{2}$ College of Arts and Sciences, Shatt Al-Arab University, Iraq \\ k.norliza,ruhana,haryani@uum.edu.my, \\ ayad_mohammed@ahsgs.uum.edu.my
}

\begin{abstract}
Citations have been an acceptable journal performance metric used by many indexing databases for inclusion and discontinuation of journals in their list. Therefore, editorial teams must maintain their journal performance by increasing article citations for continuous content indexing in the databases. With this aim in hand, this study intended to assist the editorial team of the Journal of Information and Communication Technology (JICT) in increasing the performance and impact of the journal. Currently, the journal has suffered from low citation count, which may jeopardise its sustainability. Past studies in library science suggested a positive correlation between keywords and citations. Therefore, keyword and topic analyses could be a solution to address the issue of journal citation. This article described a scientometric analysis of emerging topics in general computer science, the Scopus subject area for which JICT is indexed. This study extracted bibliometric data of the top $10 \%$ journals in the subject area to create a dataset of 5,546 articles. The results of the study suggested ten emerging topics in computer science that can
\end{abstract}


be considered by the journal editorial team in selecting articles and a list of highly used keywords in articles published in 2019 and 2020 (as of 15 April 2020). The outcome of this study might be considered by the JICT editorial team and other journals in general computer science that suffer from a similar issue.

Keywords: Scientometrics, scientometric analysis, bibliometrics, citation analysis, research trends.

\section{INTRODUCTION}

Journals are an essential source of information and knowledge for scientific studies that make a pool of literature content. Each journal has its editorial team that receives article submission from authors and selects suitable reviewers for the peer-review process. The selected reviewers of the articles provide an evaluation report of the suitability of the submitted articles to be published by the journal based on their area of expertise. This process ensures that the journals publish articles that meet scholarly standards. The number of journals keeps increasing from time to time, which causes massive articles found in the literature with different quality and standard. Therefore, many institutions and researchers have proposed journal evaluation metrics to facilitate researchers in identifying the acceptable quality of research articles as well as journals. Examples of the evaluation metrics are the Journal Impact Factor by Clarivate Analytics and CiteScore by Scopus, which are the major indexing databases. These evaluation metrics provide guidelines to researchers on the acceptable standard of scholarly content. Journal performance also reflects the reputation and achievement of the publishers or institutions.

One of the standard journal performance metrics is the citation counts of articles published by a journal (Moed \& Van Leeuwen, 1995) that could serve as a quality indicator (Cole \& Cole, 1971). The number of citations has been an acceptable journal performance metric since 1971 based on the evaluation study of sociological research by Cole and Cole (1971). Indexing databases normalise the number of citations with the corresponding number of articles that the journal published in a specific period to obtain accurate and unbiased metrics. The total number of citations is still relevant and useful to date. Prominent indexing databases such as Scopus and Clarivate (formerly known as ISI) used it as one of the performance metrics to determine inclusion or discontinuation of journals from their lists. The indexing databases annually re-evaluate the number of citations received by the journals along with other metrics such as publication concern and discontinue indexing the low-performing journals (Krauskopf, 2018). The purpose of the re-evaluation is to maintain active and performing journals in their databases. The indexing databases will update their list of discontinued journals on their website. For 
example, Scopus published a list of discontinued journals that can be accessed fromhttps://www.elsevier.com/_data/assets/excel_doc/0005/877523 Discontinued-sources-from-Scopus.xlsx. The list contains 572 journals that had been discontinued since 2009 (as of 20 February 2020). Scopus discontinued 166 journals due to citation-related metrics such as low citations as compared to peer journals in the same subject field and high self-citation rate. The discontinued list denotes the possibility of a journal content that will not be indexed by the indexing databases when it could not reach the minimum number of citations in a year. Therefore, improving journal performance through citation count is necessary for the editorial team of journals listed in the indexing databases.

With this aim in hand, this study intends to support the needs for improving the performance of the Journal of Information and Communication Technology (JICT) published by Universiti Utara Malaysia Press (http:// www.jict.uum.edu.my). The journal published its first issue in 2002 and was further indexed in Scopus's general computer science subject area in 2011. In analysing the performance of JICT, the 2018 Scopus CiteScore metrics ranked the journal as number 113 of 206 journals in the general computer science with CiteScore of 0.9, which positions it in the third quartile of the subject area. Looking at the individual articles published by the journal, a study conducted by Shehab, Khader, and Laouchedi (2018) received the highest citations of 23, followed by Hussain, Hashim, Nordin, and Tahir (2013) with 21 citations. Other studies such as those written by Hassan, Nasir, Khairudin, and Adon (2017), Jnr, Majid, and Romli (2018), and Yusuf-Asaju, Dahalin, and Ta'a (2018) had citations above ten, respectively. To date, $27 \%$ of the 141 articles published in JICT received no citations. The overall journal achievement is relatively low as compared to other new journals in the same subject area. Due to this condition, the journal editorial team works continuously to improve the impact of the journal, especially in increasing the journal's citations in the coming years.

The number of citations received by an article is evidence of how frequent the content of the article is referred by other researchers in the field (Pechlaner, Zehrer, Matzler, \& Abfalter, 2004). Consequently, it demonstrates the overall journal's performance in publishing relevant scientific studies for research literature content. In scientific research, new topics and concepts evolve over time; therefore, studying such topic evolution is necessary to ensure the relevancy and effective dissemination of scientific research output (He et al., 2009). On the other hand, topic evolution studies suggested that the temporal dimension is a significant feature for literature content (Yan, Tang, Liu, Shan, \& Li, 2011). In other words, new topics of study in a particular field emerge and adapt in the literature content over time, while some topics are obsolete. The computer science discipline is a fast-growing field of study where many new topics evolve and emerge within a short time (Hazra, Singh, Goyal, Adhikari, \& Mukherjee, 2019). Therefore, there is a need for the 
JICT editorial team to identify the current topics in computer science so that the journal can publish relevant articles that could attract other researchers' attention in referring to the published content. Eventually, it can increase the journal's citation.

The present study aims to address the issue of JICT's low citation count, as described in the previous paragraph. Therefore, the researchers conducted a scientometric analysis to identify emerging topics in computer science. It is a quantitative study to analyse the literature and reveal trends in specific areas or disciplines (Wang, Xue, Zhao, \& Wang, 2018). The objective of the study is to analyse the emerging topics and trends of scientific research in general computer science, which can be used by the JICT editorial team in selecting up-to-date studies for publication. It can help the team to select the trending research topics and thus avoid obsolete studies that receive no attention from the researchers in the discipline. The next section describes the methodology in conducting the scientometric analysis, followed by the results of the study. Finally, the last section summarises the results and discusses future works.

\section{METHODOLOGY}

This section presents the overall process and procedure in conducting the scientometric analysis covering the research questions, the methods and tools used for the study, the source of data and dataset construction as well as the procedure for selecting the samples for the study.

\section{Research Questions}

The main objective of this study is to analyse the emerging topics and trends of scientific research in general computer science. Therefore, the study formulated the following research questions (RQ) to guide its implementation and analysis:

RQ1 - What are the emerging topics in general computer science?

RQ2 - What are researchers' areas of interest in general computer science?

RQ3 - What are the characteristics of the most recent impactful scientific research in general computer science?

\section{Methods and Tools}

The generic process of conducting a scientometric analysis comprises four stages, namely (1) metadata extraction; (2) data pre-processing; (3) data processing and analysis; and (4) result visualisation (Qasim, 2017). Figure 1 illustrates the process and the tools in conducting this study. The software tools used in the study include Microsoft Excel, R Studio, Orange 3.25.0, and IBM SPSS 25. The study derived the bibliometric data from Scopus. 


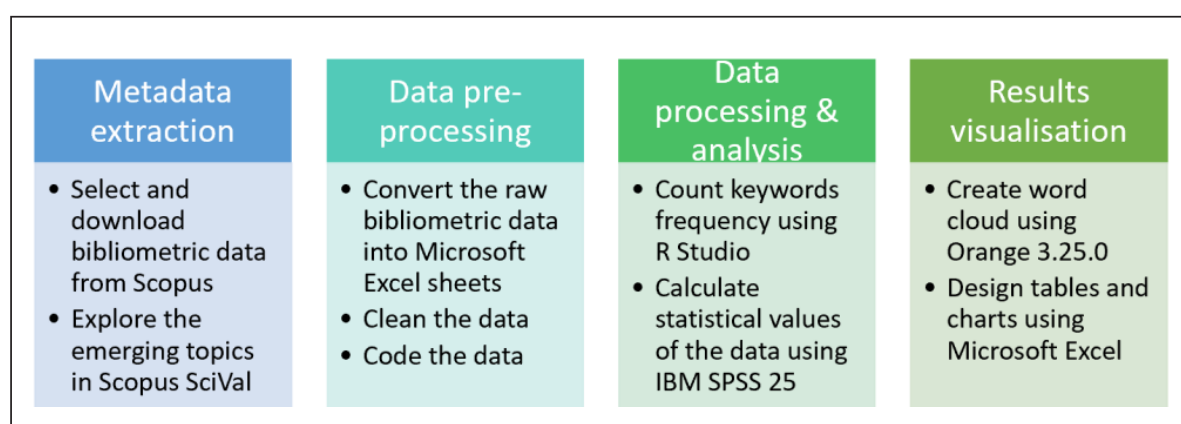

Figure 1. The process of conducting the scientometric analysis.

\section{Data and Dataset}

The bibliometric data comprised the authors, title, journal title, year of publication, volume, issue, page number, cited by, author keywords, indexed keywords, and types of article. The study omitted other bibliometric data that were irrelevant to the analysis. In Scopus, the computer science discipline encompassed 13 subject areas as listed in Table 1. As of 15 April 2020, Scopus indexed 1,922 journals in the computer science discipline. This number did not include book series, conference proceedings, and trade reports.

\section{Table 1}

Number of journals in computer science subject area

\begin{tabular}{lc}
\hline \multicolumn{1}{c}{ Computer Science Subject Area } & Number of Journals \\
\hline Artificial Intelligence & 202 \\
Computational Theory and Mathematics & 146 \\
Computer Graphics and Computer-Aided Design & 86 \\
Computer Networks and Communications & 341 \\
Computer Science (miscellaneous) & 66 \\
Computer Science Applications & 668 \\
Computer Vision and Pattern Recognition & 90 \\
General Computer Science & $\mathbf{2 7 7}$ \\
Hardware and Architecture & 170 \\
Human-Computer Interaction & 119 \\
Information Systems & 319 \\
Signal Processing & 118 \\
Software & 397 \\
\hline
\end{tabular}


JICT is listed in Scopus's general computer science subject area together with other 276 journals. The subject area reflects its name where it contains multidisciplinary journals that reported studies in a combination of computer science with other disciplines. This includes mathematics, education, engineering, law, business, management and accounting, social sciences, architecture, linguistics, library studies, agriculture, biological sciences, and history. This study utilised the Scopus data from the general computer science subject area in creating a dataset of articles to identify the emerging topics. The dataset contained bibliometric data of 5,546 articles published by 24 journals. These articles were published in 2019 up until 15 April 2020. The following subsection describes the selection procedure for the dataset.

\section{Selection Procedure}

The following selection rules have been applied in the analysis when creating the dataset:

1. Selecting the top $10 \%$ of journals in the general computer science subject area. Table 2 lists the selected journals and publishers.

2. Limiting the type of publication to journals only. The study has excluded other types of publications, such as conference proceedings, book series, and trade publications.

3. Limiting the journal articles published in 2019 and 2020 (as of 15 April 2020). The study has excluded other years.

\section{Table 2}

Top 10\% journals in general computer science (based on 2018 CiteScore metrics)

\begin{tabular}{lcc}
\hline \multicolumn{1}{c}{ Journal } & $\begin{array}{c}\mathbf{2 0 1 9 - 2 0 2 0} \\
\text { Documents }\end{array}$ & Publisher \\
\hline IEEE Transactions on Smart Grid & 679 & IEEE \\
ACM Computing Surveys & 185 & ACM \\
Computer Science Review & 20 & Elsevier \\
Swarm and Evolutionary Computation & 266 & Elsevier \\
Computers and Education & 349 & Elsevier \\
Computers in Industry & 167 & Elsevier \\
Wiley Interdisciplinary Reviews: Data & 80 & Wiley-Blackwell \\
Mining and Knowledge Discovery & 1,192 & \\
European Journal of Operational Research & & Elsevier \\
\hline
\end{tabular}




\begin{tabular}{|c|c|c|}
\hline Journal & $\begin{array}{l}2019-2020 \\
\text { Documents }\end{array}$ & Publisher \\
\hline IEEE Access & 0 & IEEE \\
\hline Foundations and Trends in Databases & 0 & Now Publishers Inc. \\
\hline Computers and Industrial Engineering & 947 & Elsevier \\
\hline Computers and Security & 333 & Elsevier \\
\hline Computers and Operations Research & 369 & Elsevier \\
\hline $\begin{array}{l}\text { Human-centric Computing and } \\
\text { Information Sciences }\end{array}$ & 54 & Springer Nature \\
\hline Engineering & 204 & Elsevier \\
\hline $\begin{array}{l}\text { International Journal of Bio-Inspired } \\
\text { Computation }\end{array}$ & 47 & Inderscience \\
\hline ACM Transactions on Computer Systems & 9 & $\mathrm{ACM}$ \\
\hline $\begin{array}{l}\text { ACM Transactions on Knowledge } \\
\text { Discovery from Data }\end{array}$ & 85 & $\mathrm{ACM}$ \\
\hline $\begin{array}{l}\text { International Journal of Computational } \\
\text { Intelligence Systems }\end{array}$ & 116 & Atlantis Press \\
\hline $\begin{array}{l}\text { ACM Transactions on Computing } \\
\text { Education }\end{array}$ & 50 & $\mathrm{ACM}$ \\
\hline $\begin{array}{l}\text { International Journal of Health } \\
\text { Geographics }\end{array}$ & 40 & Springer Nature \\
\hline SIAM Journal on Computing & 59 & $\begin{array}{c}\text { Society for Industrial } \\
\text { and Applied } \\
\text { Mathematics }\end{array}$ \\
\hline Computer Science Education & 27 & Taylor \& Francis \\
\hline Information Technology and Tourism & 41 & Springer Nature \\
\hline $\begin{array}{l}\text { Computational Intelligence and } \\
\text { Neuroscience }\end{array}$ & 173 & Hindawi \\
\hline Construction Innovation & 54 & Emerald \\
\hline
\end{tabular}

Table 2 shows the top $10 \%$ of journals listed in general computer science based on the Scopus 2018 CiteScore metrics. Scopus had discontinued indexing a journal named Foundations and Trends in Databases in 2018. The contents of 2019 and 2020 of this journal were no longer available in Scopus; therefore, this journal did not have any articles included in the dataset. On the other hand, IEEE Access published 17,379 articles in 2019 and 4,769 articles in 2020 (as of 15 April 2020) and made a total of 18,148 articles for both years. This number was three times higher than the other 24 journals that had published in the same period. The articles published by IEEE Access can make a separate dataset. For this reason, the present study has excluded the journal from the dataset. 


\section{ANALYSIS AND RESULTS}

This section elaborates the findings of the scientometric analysis conducted for this study. The study calculated the descriptive statistics of the dataset. The citations' mean and standard deviation of the 5,546 articles were 2.46 and 5.283 , respectively. On the other hand, the mean for the number of authors and indexed keywords was 4.66 and 13.55, respectively. This section contains three subsections based on the three defined RQs.

\section{What are the emerging topics in computer science?}

The study used SciVal, a Scopus tool for analysing research performance in identifying the emerging topics in computer science. The tool discovered 37 newly emerged topics for 2019 in the whole world. The SciVal algorithm identified the emerging topics based on a remarkable growth of published articles in certain areas between 2014 and 2018 that have attracted funding from various agencies. The computer science discipline has ten emerging topics; the highest number of emerging topics as compared to other disciplines. Table 3 lists the emerging topics in computer science from the existing ones, the number of articles in the identified new topics, the value of field-weighted citation impact, and the prominence percentile of the topics. Field-weighted citation impact represents "the ratio of the total citations actually received by the denominator's output, and the total citations that would be expected based on the average of the subject field" (Scopus Support Center, 2019). Prominence percentile shows the rank of the topics that combined three metrics, including citation counts, views counts, and CiteScore (Elsevier, 2020).

\section{Table 3}

Emerging topics in computer science based on SciVal (as of 15 April 2020)

\begin{tabular}{|c|c|c|c|}
\hline $\begin{array}{l}\text { Emerging topics in computer } \\
\text { science }\end{array}$ & $\begin{array}{l}\text { Number of } \\
\text { articles }\end{array}$ & $\begin{array}{l}\text { Field-weighted } \\
\text { citation impact }\end{array}$ & $\begin{array}{l}\text { Prominence } \\
\text { percentile }\end{array}$ \\
\hline $\begin{array}{l}\text { Models } \rightarrow \text { Computer vision } \rightarrow \text { Deep } \\
\text { generative }\end{array}$ & 3310 & 3.91 & 99.829 \\
\hline $\begin{array}{c}\text { Convolution } \rightarrow \text { Particle } \\
\text { accelerators } \rightarrow \text { Convolutional } \\
\text { neural network accelerator }\end{array}$ & 2505 & 3.50 & 99.604 \\
\hline $\begin{array}{c}\text { Models } \rightarrow \text { Computational } \\
\text { linguistics } \rightarrow \text { Neural } \\
\text { machine translation }\end{array}$ & 1935 & 3.09 & 98.337 \\
\hline
\end{tabular}




\begin{tabular}{cccc}
\hline $\begin{array}{c}\text { Emerging topics in computer } \\
\text { science }\end{array}$ & $\begin{array}{c}\text { Number of } \\
\text { articles }\end{array}$ & $\begin{array}{c}\text { Field-weighted } \\
\text { citation impact }\end{array}$ & $\begin{array}{c}\text { Prominence } \\
\text { percentile }\end{array}$ \\
\hline $\begin{array}{c}\text { Face recognition } \rightarrow \text { Neural } \\
\text { networks } \rightarrow \text { Labelled faces in the } \\
\text { wild dataset } \\
\quad \text { Cloud }\end{array}$ & 895 & 3.19 & 98.081 \\
$\begin{array}{c}\quad \text { computation } \\
\text { computing } \rightarrow \text { Tensors } \rightarrow \text { Deep }\end{array}$ & 131 & 4.42 & 96.356 \\
$\begin{array}{c}\text { Neural networks } \rightarrow \text { Convolution } \rightarrow \\
\text { Unsupervised learning }\end{array}$ & 218 & 3.73 & 94.055 \\
$\begin{array}{c}\text { Students } \rightarrow \text { Research } \rightarrow \text { Learning } \\
\text { media }\end{array}$ & 262 & 3.71 & 91.536 \\
$\begin{array}{c}\text { Internet } \rightarrow \text { Network security } \rightarrow \\
\text { Distributed denial-of-service } \\
\text { attacks }\end{array}$ & 135 & 2.79 & 90.810 \\
$\quad \begin{array}{c}\text { Sensor nodes } \rightarrow \text { Genetic } \\
\text { algorithms } \rightarrow \text { Wireless sensor } \\
\text { networks }\end{array}$ & 125 & 5.82 & 90.525 \\
$\begin{array}{c}\text { Applications } \rightarrow \text { Internet } \rightarrow \text { Wireless } \\
\text { network }\end{array}$ & 103 & 2.36 & 88.119 \\
\hline$\quad$ & & & \\
\hline
\end{tabular}

A closer look into the ten emerging topics in computer science listed in Table 3 revealed that those topics were the subfields of artificial intelligence techniques and computer networks. In detail, topics such as "deep generative", "convolutional neural network accelerator", "neural machine translation", "labelled faces in the wild dataset", "deep computation", and "unsupervised learning" were the emerging topics related to artificial intelligence techniques. On the other hand, "wireless network", "wireless sensor networks", and "distributed denial-of-service attacks" were the emerging topics related to computer network. Nevertheless, "learning media" is a multidisciplinary topic related to education and computer science.

\section{What are the recent researchers' areas of interest in general computer science?}

The study answered this RQ by analysing the keywords in the 5,546 articles of the dataset to obtain the researchers' areas of interest in general computer science. Scopus provided two types of keyword, namely author keyword and indexed keyword. Author keywords are the keywords defined by authors in the articles. The study used R Studio to perform a frequency count on the keywords in the dataset. The study removed the hyphen in the keyword phrase to maintain data consistency for the frequency count. The dataset yielded a total of 25,849 author keywords. The keyword length differed, covering from 
one to a maximum of 11 words. As stated earlier, each article in the dataset had an average of 4.66 author keywords. 2-word phrase was the highest with 12,550 keywords. This was followed by 3 -word and 1 -word phrases with 6,328 and 4,602, respectively. Table 4 lists the size or length of the keyword with its frequency. This study found that an article by Li and Chen (2020) had 11 words for representing a keyword phrase. It is "two-area four-machine and 16-machine 68-bus power system".

\section{Table 4}

The number of author keywords derived from the dataset

\begin{tabular}{cc}
\hline Size & Frequency \\
\hline 1-word & 4,602 \\
2-word & 12,550 \\
3-word & 6,328 \\
4-word & 1,792 \\
5-word & 416 \\
6-word & 114 \\
7-word & 32 \\
8-word & 8 \\
9-word & 3 \\
10-word & 3 \\
11-word & 1 \\
\hline TOTAL & $\mathbf{2 5 , 8 4 9}$ \\
\hline
\end{tabular}

For the 1-word phrase size, "scheduling" had the highest frequency with 135 times of occurrence in the dataset, followed by "optimization", and "heuristics" with 83 and 63, respectively. Table 5 shows the frequency (F) of the keywords found from the dataset for 1-word, 2-word, and 3-word. The highest frequency for 4-word length keyword was mixed-integer linear programming with 44 occurrences. The occurrences of 5-word, 6-word, 7-word, 8-word, 9-word, and 10-word were not too frequent; therefore, the study omitted those keywords from further analysis. For 2-word, "machine learning", "game theory", and "combinatorial optimization" were the top three author keywords. On the other hand, "supply chain management", "data envelopment analysis", and "multi-objective optimization" were the top three 3-word author keywords. 


\section{Table 5}

The top 50 keywords for 1-word, 2-word, and 3-word length

\begin{tabular}{|c|c|c|c|c|c|}
\hline \multicolumn{2}{|l|}{ 1-word } & \multicolumn{2}{|l|}{ 2-word } & \multicolumn{2}{|l|}{ 3-word } \\
\hline Keyword & $\mathbf{F}$ & Keyword & $\mathbf{F}$ & Keyword & $\mathbf{F}$ \\
\hline scheduling & 135 & machine learning & 142 & $\begin{array}{l}\text { supply chain } \\
\text { management }\end{array}$ & 122 \\
\hline optimization & 83 & game theory & 96 & $\begin{array}{l}\text { data envelopment } \\
\text { analysis }\end{array}$ & 99 \\
\hline heuristics & 63 & $\begin{array}{l}\text { combinatorial } \\
\text { optimization }\end{array}$ & 82 & $\begin{array}{l}\text { multi objective } \\
\text { optimization }\end{array}$ & 58 \\
\hline metaheuristics & 54 & deep learning & 79 & $\begin{array}{l}\text { interactive learning } \\
\text { environments }\end{array}$ & 52 \\
\hline simulation & 54 & integer programming & 73 & $\begin{array}{l}\text { improving classroom } \\
\text { teaching }\end{array}$ & 50 \\
\hline microgrid & 53 & $\begin{array}{l}\text { teaching/learning } \\
\text { strategies }\end{array}$ & 67 & internet of things & 40 \\
\hline logistics & 48 & robust optimization & 65 & $\begin{array}{l}\text { mixed integer } \\
\text { programming }\end{array}$ & 40 \\
\hline pricing & 48 & $\begin{array}{l}\text { stochastic } \\
\text { programming }\end{array}$ & 57 & $\begin{array}{l}\text { particle swarm } \\
\text { optimization }\end{array}$ & 39 \\
\hline routing & 48 & demand response & 55 & media in education & 35 \\
\hline security & 45 & smart grid & 55 & $\begin{array}{l}\text { computer mediated } \\
\text { communication }\end{array}$ & 27 \\
\hline classification & 41 & genetic algorithm & 53 & $\begin{array}{l}\text { vehicle routing } \\
\text { problem }\end{array}$ & 27 \\
\hline inventory & 40 & industry 4.0 & 52 & branch and bound & 26 \\
\hline transportation & 39 & big data & 49 & branch and price & 24 \\
\hline blockchain & 38 & data mining & 49 & $\begin{array}{l}\text { group decision } \\
\text { making }\end{array}$ & 23 \\
\hline uncertainty & 37 & cloud computing & 47 & $\begin{array}{l}\text { human computer } \\
\text { interface }\end{array}$ & 22 \\
\hline finance & 35 & pedagogical issues & 44 & $\begin{array}{l}\text { systematic literature } \\
\text { review }\end{array}$ & 22 \\
\hline sustainability & 30 & differential evolution & 41 & $\begin{array}{l}\text { ant colony } \\
\text { optimization }\end{array}$ & 21 \\
\hline clustering & 28 & dynamic programming & 39 & branch and cut & 21 \\
\hline energy & 27 & artificial intelligence & 38 & $\begin{array}{l}\text { multiple objective } \\
\text { programming }\end{array}$ & 21 \\
\hline privacy & 27 & health services & 36 & $\begin{array}{l}\text { post secondary } \\
\text { education }\end{array}$ & 21 \\
\hline
\end{tabular}




\begin{tabular}{|c|c|c|c|c|c|}
\hline \multicolumn{2}{|l|}{ 1-word } & \multicolumn{2}{|l|}{ 2-word } & \multicolumn{2}{|l|}{ 3-word } \\
\hline Keyword & $\mathbf{F}$ & Keyword & $\mathbf{F}$ & Keyword & $\mathbf{F}$ \\
\hline location & 26 & distributed control & 30 & $\begin{array}{l}\text { many objective } \\
\text { optimization }\end{array}$ & 20 \\
\hline makespan & 25 & $\begin{array}{l}\text { evolutionary } \\
\text { algorithm }\end{array}$ & 30 & $\begin{array}{l}\text { decision support } \\
\text { systems }\end{array}$ & 19 \\
\hline maintenance & 24 & vehicle routing & 30 & $\begin{array}{l}\text { demand side } \\
\text { management }\end{array}$ & 18 \\
\hline survey & 24 & risk management & 29 & $\begin{array}{l}\text { distributed energy } \\
\text { resources }\end{array}$ & 18 \\
\hline cybersecurity & 23 & decision analysis & 28 & $\begin{array}{l}\text { multiple criteria } \\
\text { analysis }\end{array}$ & 18 \\
\hline heuristic & 23 & local search & 28 & $\begin{array}{l}\text { cyber physical } \\
\text { systems }\end{array}$ & 17 \\
\hline manufacturing & 23 & literature review & 27 & $\begin{array}{l}\text { markov decision } \\
\text { process }\end{array}$ & 17 \\
\hline microgrids & 23 & $\begin{array}{l}\text { cooperative/ } \\
\text { collaborative learning }\end{array}$ & 25 & $\begin{array}{l}\text { variable neighborhood } \\
\text { search }\end{array}$ & 17 \\
\hline forecasting & 22 & electric vehicles & 25 & $\begin{array}{l}\text { approximate dynamic } \\
\text { programming }\end{array}$ & 15 \\
\hline remanufacturing & 22 & elementary education & 24 & big data analytics & 15 \\
\hline networks & 21 & energy storage & 24 & $\begin{array}{l}\text { productivity and } \\
\text { competitiveness }\end{array}$ & 15 \\
\hline analytics & 20 & feature selection & 24 & $\begin{array}{l}\text { monte carlo } \\
\text { simulation }\end{array}$ & 14 \\
\hline malware & 20 & network security & 24 & optimal power flow & 14 \\
\hline efficiency & 19 & tabu search & 24 & $\begin{array}{l}\text { statistical process } \\
\text { control }\end{array}$ & 14 \\
\hline iot & 19 & project scheduling & 23 & $\begin{array}{l}\text { discrete event } \\
\text { simulation }\end{array}$ & 13 \\
\hline matheuristic & 18 & supply chain & 23 & $\begin{array}{l}\text { natural language } \\
\text { processing }\end{array}$ & 13 \\
\hline queueing & 18 & cyber security & 21 & $\begin{array}{l}\text { model predictive } \\
\text { control }\end{array}$ & 12 \\
\hline decomposition & 15 & project management & 21 & $\begin{array}{l}\text { supply chain } \\
\text { coordination }\end{array}$ & 12 \\
\hline marketing & 15 & $\begin{array}{l}\text { benders } \\
\text { decomposition }\end{array}$ & 20 & cyber physical system & 11 \\
\hline resilience & 15 & $\begin{array}{l}\text { evolutionary } \\
\text { computation }\end{array}$ & 20 & deep neural network & 11 \\
\hline review & 15 & linear programming & 20 & multi agent systems & 11 \\
\hline packing & 14 & secondary education & 20 & $\begin{array}{l}\text { artificial neural } \\
\text { networks }\end{array}$ & 10 \\
\hline
\end{tabular}




\begin{tabular}{|c|c|c|c|c|c|}
\hline \multicolumn{2}{|l|}{ 1-word } & \multicolumn{2}{|l|}{ 2-word } & \multicolumn{2}{|l|}{ 3-word } \\
\hline Keyword & $\mathbf{F}$ & Keyword & $\mathbf{F}$ & Keyword & $\mathbf{F}$ \\
\hline authentication & 13 & swarm intelligence & 20 & $\begin{array}{l}\text { large scale } \\
\text { optimization }\end{array}$ & 10 \\
\hline consensus & 13 & distribution network & 19 & $\begin{array}{l}\text { phasor measurement } \\
\text { units }\end{array}$ & 10 \\
\hline learning & 13 & electric vehicle & 19 & $\begin{array}{l}\text { support vector } \\
\text { machine }\end{array}$ & 10 \\
\hline ontology & 13 & $\begin{array}{l}\text { stochastic } \\
\text { optimization }\end{array}$ & 19 & $\begin{array}{l}\text { traveling salesman } \\
\text { problem }\end{array}$ & 10 \\
\hline robustness & 13 & droop control & 18 & $\begin{array}{l}\text { wireless sensor } \\
\text { networks }\end{array}$ & 10 \\
\hline fairness & 12 & revenue management & 18 & artificial bee colony & 9 \\
\hline
\end{tabular}

The information in Table 5 listed the keywords based on the keyword size or length. The combined keywords of multiple lengths were sorted descendingly as in Table 6. The top three author keywords in general computer science were "machine learning", "scheduling", and "supply chain management". Other author keywords included "data envelopment analysis", "game theory", "optimization", "combinatorial optimization", "deep learning", "integer programming", "teaching/learning strategies", "robust optimization", and "heuristics". Figure 2 shows the word cloud of the author keywords.

\section{Table 6}

Author keywords with more than 50 occurrences

\begin{tabular}{lc}
\hline \multicolumn{1}{c}{ Keywords } & F \\
\hline machine learning & 142 \\
scheduling & 135 \\
supply chain management & 122 \\
data envelopment analysis & 99 \\
game theory & 96 \\
optimization & 83 \\
combinatorial optimization & 82 \\
deep learning & 79 \\
integer programming & 73 \\
teaching/learning strategies & 67 \\
robust optimization & 65 \\
\hline
\end{tabular}




\begin{tabular}{ll}
\hline \multicolumn{1}{c}{ Keywords } & F \\
\hline heuristics & 63 \\
internet of things (iot) & 59 \\
multi objective optimization & 58 \\
stochastic programming & 57 \\
demand response & 55 \\
smart grid & 55 \\
metaheuristics & 54 \\
simulation & 54 \\
microgrid & 53 \\
genetic algorithm & 53 \\
industry 4.0 & 52 \\
interactive learning environments & 52 \\
improving classroom teaching & 50 \\
\hline
\end{tabular}

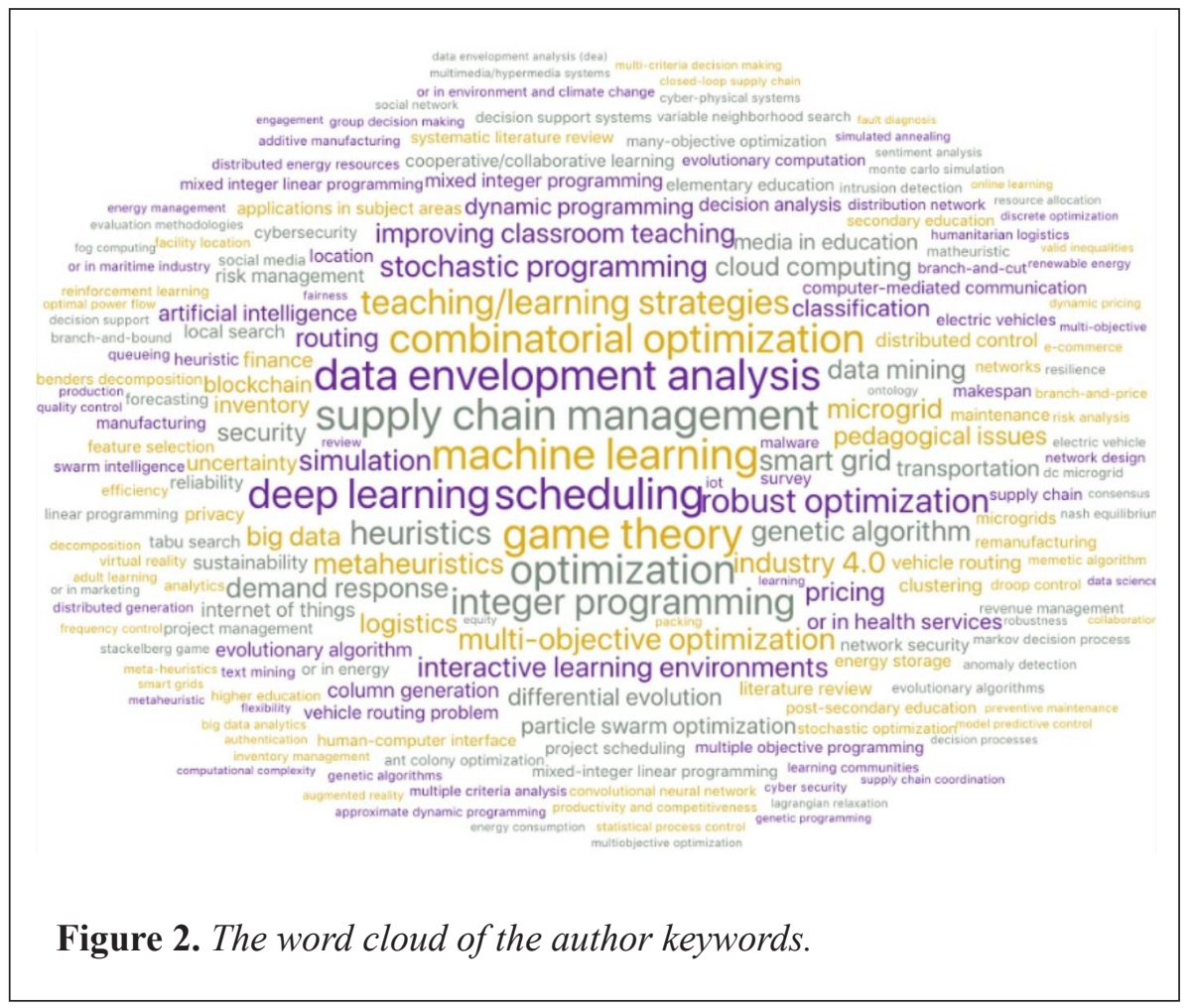

The study also analysed the indexed keyword of the 5,546 articles in the dataset. Scopus also allowed "indexed keywords" for articles included in its 
database that are chosen by content suppliers. The keywords are standardised based on public vocabularies (Scopus Support Center, 2020). Scopus did not influence both the author and indexed keywords as third parties determined them. Indexed keywords appear in various categories. Engineering and technology articles have three types of indexed keywords, namely "engineering controlled terms", "engineering uncontrolled terms", and "engineering main heading". Figure 3 shows an example of indexed keywords for an article written by Kong et al. (2019) as displayed in the Scopus website. Other types of indexed keywords include "GEOBASE Subject Index", "EMTREE Medical Term", "Regional Index", and "Medical Subject Heading".

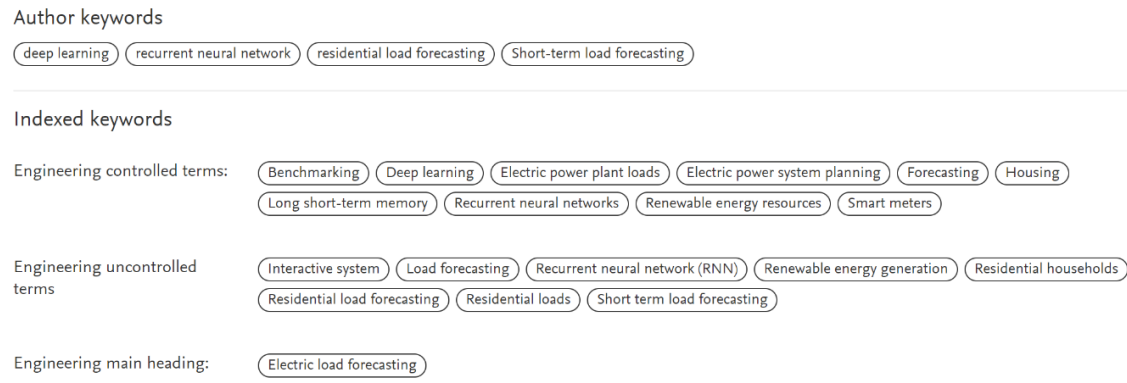

Figure 3. Examples of indexed keywords for an article written by Kong et al. (2019).

The study further analysed the frequency of the indexed terms for the 5,546 articles in the dataset. The total indexed keywords for the dataset was 74,045 . On average, an article had 13.35 indexed keywords. Chukwusa et al. (2019) had the highest number of indexed keywords with 62 in total. However, 276 articles had no indexed keywords. Table 7 lists the journals of the corresponding articles. The highest number of articles without indexed keywords came from the journal of "Human-centric Computing and Information Sciences". Only two of the articles from the journal included in the dataset had indexed keywords. Nevertheless, this study did not cover the reasons behind the absence of indexed keywords for the articles. 


\section{Table 7}

The number of articles without indexed keywords and their corresponding journals

\section{Journals}

\begin{tabular}{lc}
\hline \multicolumn{1}{c}{ Journals } & $\begin{array}{c}\text { Number of articles without } \\
\text { indexed keyword }\end{array}$ \\
\hline ACM Transactions on Computing Education & 1 \\
Computational Intelligence and Neuroscience & 3 \\
Computer Science Education & 27 \\
Computers and Education & 6 \\
Computers and Industrial Engineering & 12 \\
Computers and Operations Research & 3 \\
Computers and Security & 4 \\
Computers in Industry & 5 \\
Engineering & 48 \\
European Journal of Operational Research & 17 \\
Human-centric Computing and Information & 52 \\
Sciences & 1 \\
IEEE Transactions on Smart Grid & 41 \\
Information Technology and Tourism & 47 \\
International Journal of Bio-Inspired Computation & 2 \\
International Journal of Health Geographics & 1 \\
SIAM Journal on Computing & 5 \\
Swarm and Evolutionary Computation & 1 \\
Wiley Interdisciplinary Reviews: Data Mining & \\
and Knowledge Discovery & \\
\hline
\end{tabular}

The occurrences of indexed keywords in the dataset had been counted. Table 8 lists the top 50 indexed keywords of the articles in the dataset with their frequency. In general, the frequency of the top indexed keywords derived from the dataset was much higher than the author keywords. The size or length of the keywords covered 1-word, 2-word, 3-word, and 4-word. The dataset did not contain keyword size or length more than 5-word. "Integer programming" had the highest frequency with 574 occurrences, followed by "decision making, and "scheduling" with 533 and 458, respectively. Other keywords such as "stochastic systems" and "optimization" appeared 401 times, respectively, in the dataset. 


\section{Table 8}

Top 50 indexed keywords in the articles

\begin{tabular}{lc}
\hline \multicolumn{1}{c}{ Indexed Keywords } & Frequency \\
\hline Integer Programming & 574 \\
Decision Making & 533 \\
Scheduling & 458 \\
Optimization & 401 \\
Stochastic Systems & 401 \\
Sales & 318 \\
Costs & 310 \\
Learning Systems & 279 \\
Genetic Algorithm & 255 \\
Surveys & 229 \\
Students & 228 \\
Micro Grid & 222 \\
Supply Chains & 222 \\
Machine Learning & 218 \\
Multiobjective Optimization & 218 \\
Commerce & 217 \\
Benchmarking & 205 \\
Human & 192 \\
Evolutionary Algorithms & 191 \\
Heuristic Algorithms & 190 \\
Manufacture & 176 \\
Stochastic Models & 171 \\
Game Theory & 165 \\
Data Mining & 161 \\
Forecasting & 161 \\
Supply Chain Management & 159 \\
Electric Power Transmission Networks & 156 \\
Linear Programming & 156 \\
Combinatorial Optimization & 154 \\
Artificial Intelligence & 153 \\
\hline &
\end{tabular}




\begin{tabular}{lc}
\hline \multicolumn{1}{c}{ Indexed Keywords } & Frequency \\
\hline Network Security & 153 \\
Problem Solving & 150 \\
Computational Experiment & 149 \\
Algorithm & 148 \\
Location & 148 \\
Heuristic Methods & 146 \\
Neural Networks & 146 \\
Learning Algorithms & 143 \\
Economic And Social Effects & 140 \\
Sensitivity Analysis & 138 \\
Teaching/learning Strategy & 133 \\
Deep Learning & 132 \\
Efficiency & 130 \\
Operational Research & 130 \\
Computer-Aided Instruction & 129 \\
Iterative Methods & 129 \\
Profitability & 127 \\
Computer Science & 125 \\
Investments & 125 \\
\hline
\end{tabular}

The study further compared the occurrences of author and indexed keywords that appeared in both categories as listed in Table 9. The keywords "scheduling" and "optimization"were found in the author and indexed keywords with a high number of occurrences. Other keywords such as "forecasting", "location", "efficiency", "metaheuristics", "logistics", "security", and "maintenance" were also found in both types of the keyword. The 1-word size was frequently found in the two types of keywords as compared to the other sizes or lengths.

\section{Table 9}

Author and indexed keywords with their frequency

\begin{tabular}{lccr}
\hline \multicolumn{1}{c}{ Keyword } & F (Author keyword) & F (Indexed keyword) \\
\hline Scheduling & 135 & 458 & \\
Optimization & 83 & 401 & \\
\hline & & & (continued)
\end{tabular}




\begin{tabular}{lcc}
\hline \multicolumn{1}{c}{ Keyword } & F (Author keyword) & F (Indexed keyword) \\
\hline Forecasting & 22 & 161 \\
Location & 26 & 148 \\
Efficiency & 19 & 130 \\
Metaheuristics & 54 & 103 \\
Heuristics & 63 & 65 \\
Logistics & 48 & 55 \\
Security & 45 & 55 \\
Maintenance & 24 & 53 \\
\hline
\end{tabular}

The researchers cross-checked the results of this study with JICT articles to compare the author keywords used in the journal. The top five author keywords in 141 JICT articles were "cloud computing" (4), "neural network" (3), "ontology" (3), "particle swarm optimization" (3), and "WCAG 2.0 " (3). The number in the brackets denotes the frequency. The study also selected the top $50 \mathrm{JICT}$ articles with the highest citations to understand their keywords. The top ten author keywords were "analytic hierarchy process" (2), "artificial neural network" (2), "biometrics" (2), "cloud computing" (2), "firefly algorithm" (2), "particle swarm optimization" (2), "SMEs" (2), "software engineering" (2), "WCAG 2.0" (2), and "web accessibility" (2). Furthermore, the study searched JICT articles with the top three author keywords in Table 6. The keywords were "machine learning", "scheduling", and "supply chain management". Table 10 summarises the JICT articles that were related to the top three author keywords with their citations. Overall, only three articles mentioned "machine learning" in their abstracts. However, two of them did not list the keyword in the keyword section. For "scheduling", two articles mentioned it in their abstract and keyword section; while one article mentioned "supply chain management" in the title. The analysis suggested that less than $1 \%$ of the articles published in JICT had the similar top author keywords listed in Table 6. 


\section{Table 10}

Top three author keywords and JICT articles with citations

\begin{tabular}{|c|c|c|c|c|}
\hline Keywords & $\begin{array}{l}\text { Title of JICT articles with } \\
\text { the keyword listed in the } \\
\text { author keyword section }\end{array}$ & $\begin{array}{l}\text { Keyword } \\
\text { listed in the } \\
\text { keyword } \\
\text { section }\end{array}$ & $\begin{array}{c}\text { Year } \\
\text { published }\end{array}$ & $\begin{array}{l}\text { Citations } \\
\text { (As of 15 } \\
\text { April 2020) }\end{array}$ \\
\hline \multirow[t]{3}{*}{$\begin{array}{l}\text { machine } \\
\text { learning }\end{array}$} & $\begin{array}{l}\text { Bayesian network of traffic } \\
\text { accidents in Malaysia }\end{array}$ & No & 2019 & 0 \\
\hline & $\begin{array}{l}\text { Intelligent cooperative } \\
\text { web caching policies for } \\
\text { media objects based on J48 } \\
\text { decision tree and Naïve } \\
\text { Bayes supervised machine } \\
\text { learning algorithms in } \\
\text { structured peer-to-peer } \\
\text { systems }\end{array}$ & Yes & 2016 & 0 \\
\hline & $\begin{array}{l}\text { Artificial fish swarm } \\
\text { optmization for multilayer } \\
\text { network learning in } \\
\text { classification problems }\end{array}$ & No & 2012 & 5 \\
\hline \multirow[t]{2}{*}{ scheduling } & $\begin{array}{l}\text { Hybrid cat swarm } \\
\text { optimization and simulated } \\
\text { annealing for dynamic } \\
\text { task scheduling on cloud } \\
\text { computing environment }\end{array}$ & Yes & 2018 & 6 \\
\hline & $\begin{array}{l}\text { A mixed integer linear } \\
\text { programming model for } \\
\text { real-time task scheduling } \\
\text { in multiprocessor computer } \\
\text { system }\end{array}$ & Yes & 2012 & 0 \\
\hline $\begin{array}{l}\text { supply chain } \\
\text { management }\end{array}$ & $\begin{array}{l}\text { Supply chain management: } \\
\text { A system dynamics } \\
\text { approach to improve } \\
\text { visibility and performance }\end{array}$ & No & 2011 & 2 \\
\hline
\end{tabular}

\section{What are the characteristics of the most recent impactful scientific research in general computer science?}

In answering this RQ, the study analysed the 5,546 articles in the dataset to identify the impact of the scientific study, indexed keywords, types of articles as well as other attributes such as the top contributors covering the authors, countries, and funding agencies. The top 100 articles with the highest citations were filtered and selected for further analysis of the characteristics mentioned 
previously. An article by Kong et al. (2019) received the highest citations of 139 (as of 15 April 2020). "IEEE Transactions on Smart Grid" published the article with four author keywords and 19 indexed keywords. Table 11 lists the other highly-cited articles in the dataset and their information. The latest articles included in the Scopus were Rauch, Linder, and Dallasega (2020) (i.e. number 90 of Table 11) and Fantini, Pinzone, and Taisch (2020) (i.e. number 30 of Table 11). The articles received 18 and 28 times of citation, respectively. Both articles were published by "Computers and Industrial Engineering". The impact of the scientific research listed in Table 11 was remarkable as the articles managed to attract a high number of citations in a short period. 


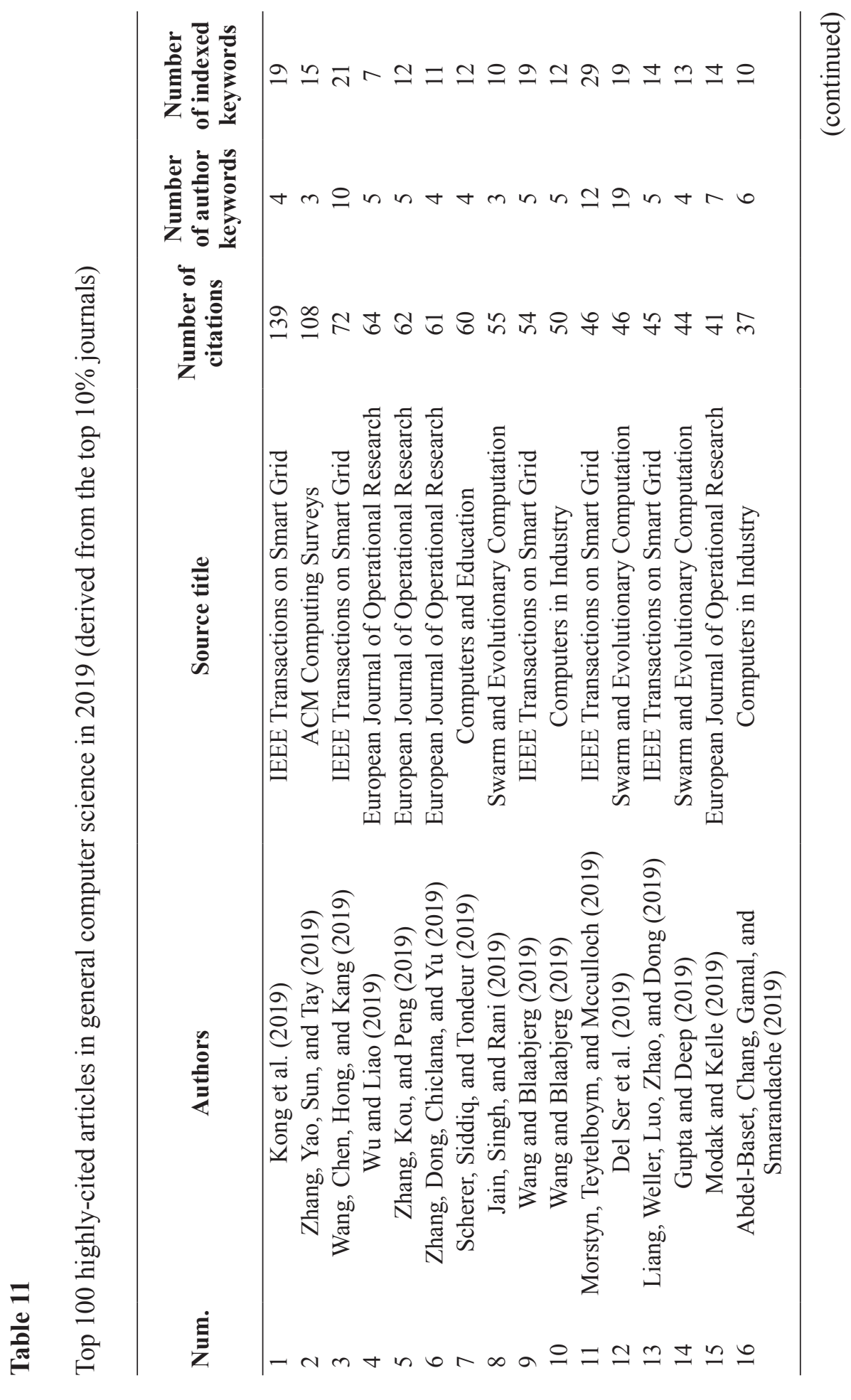




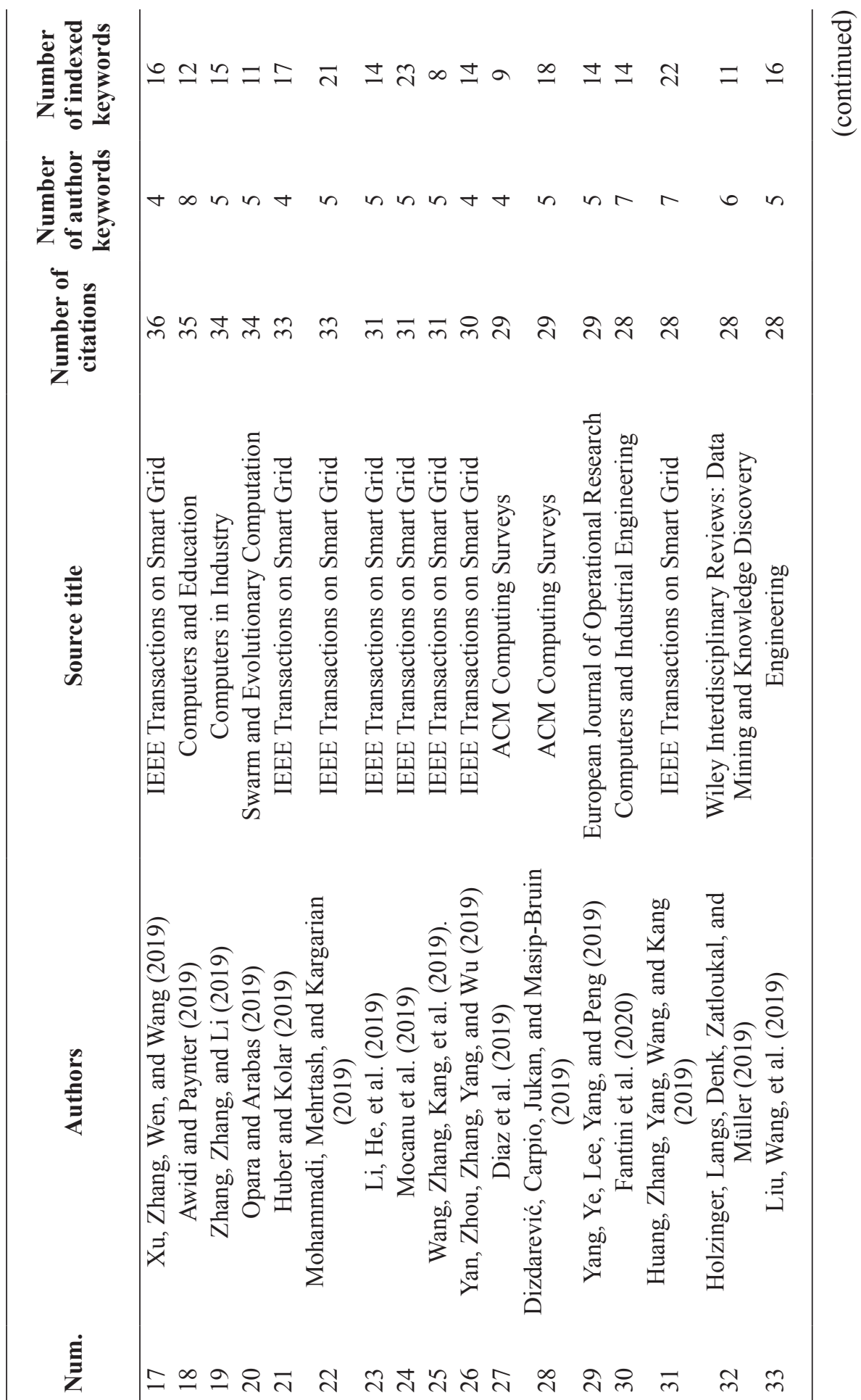




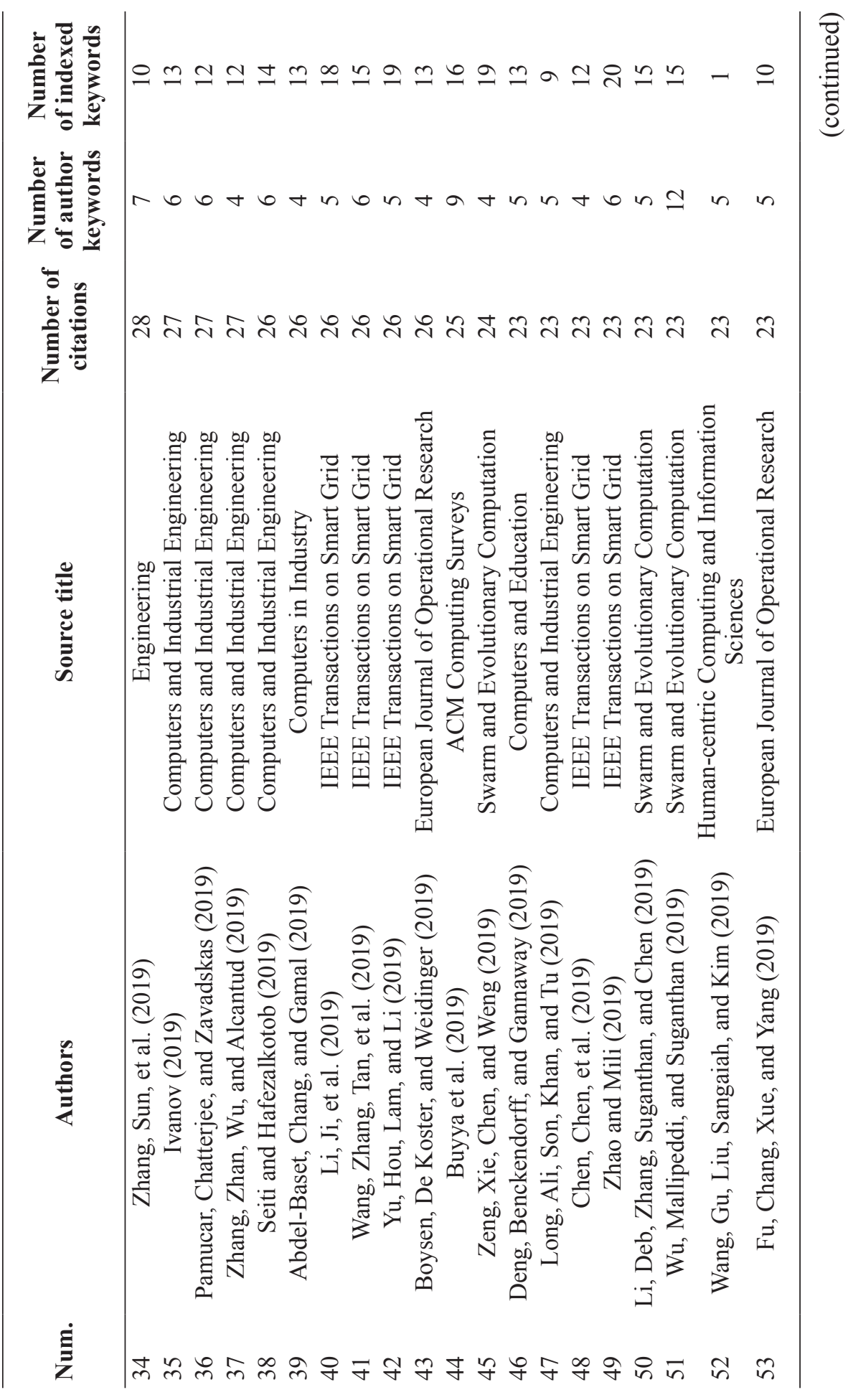




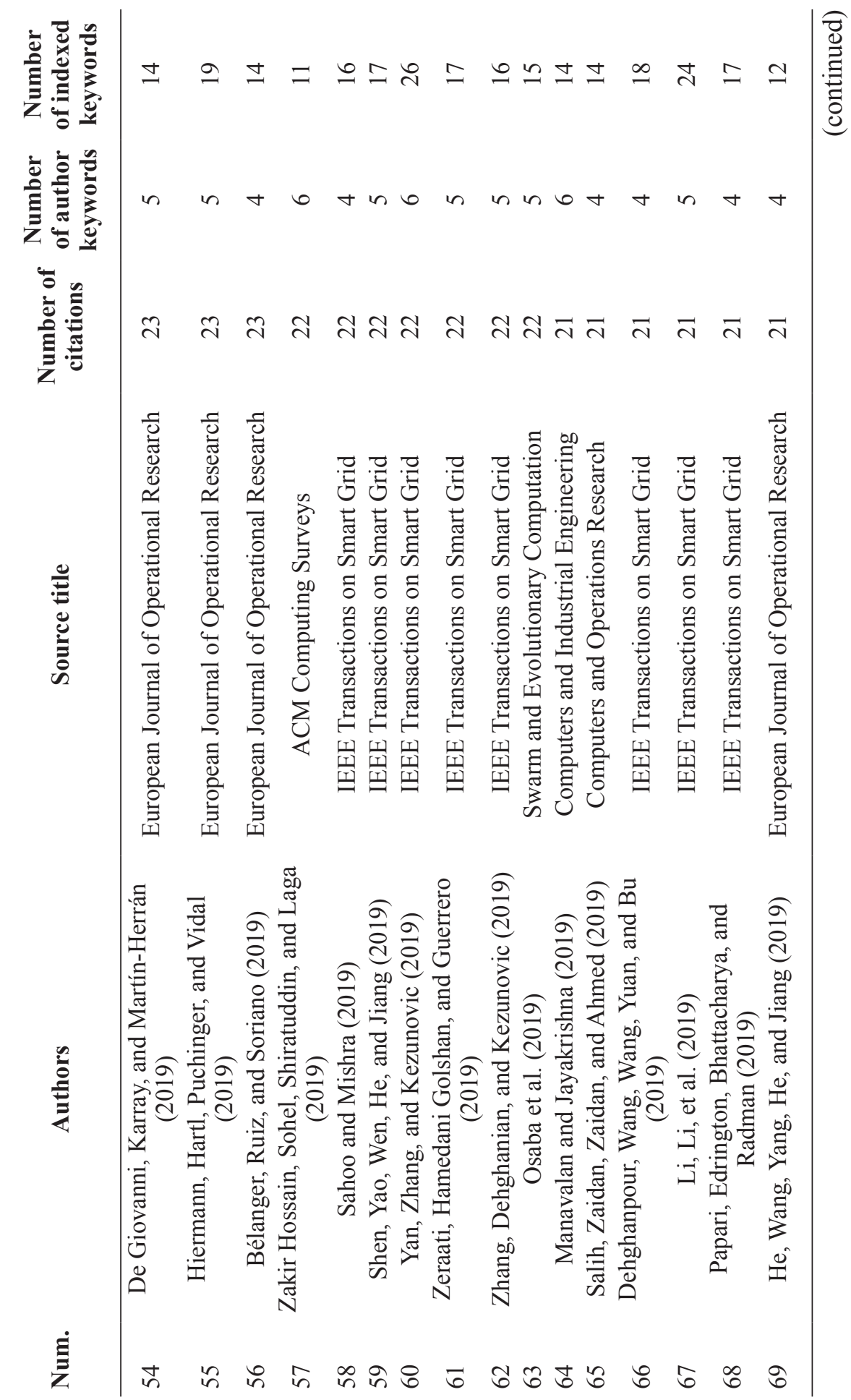




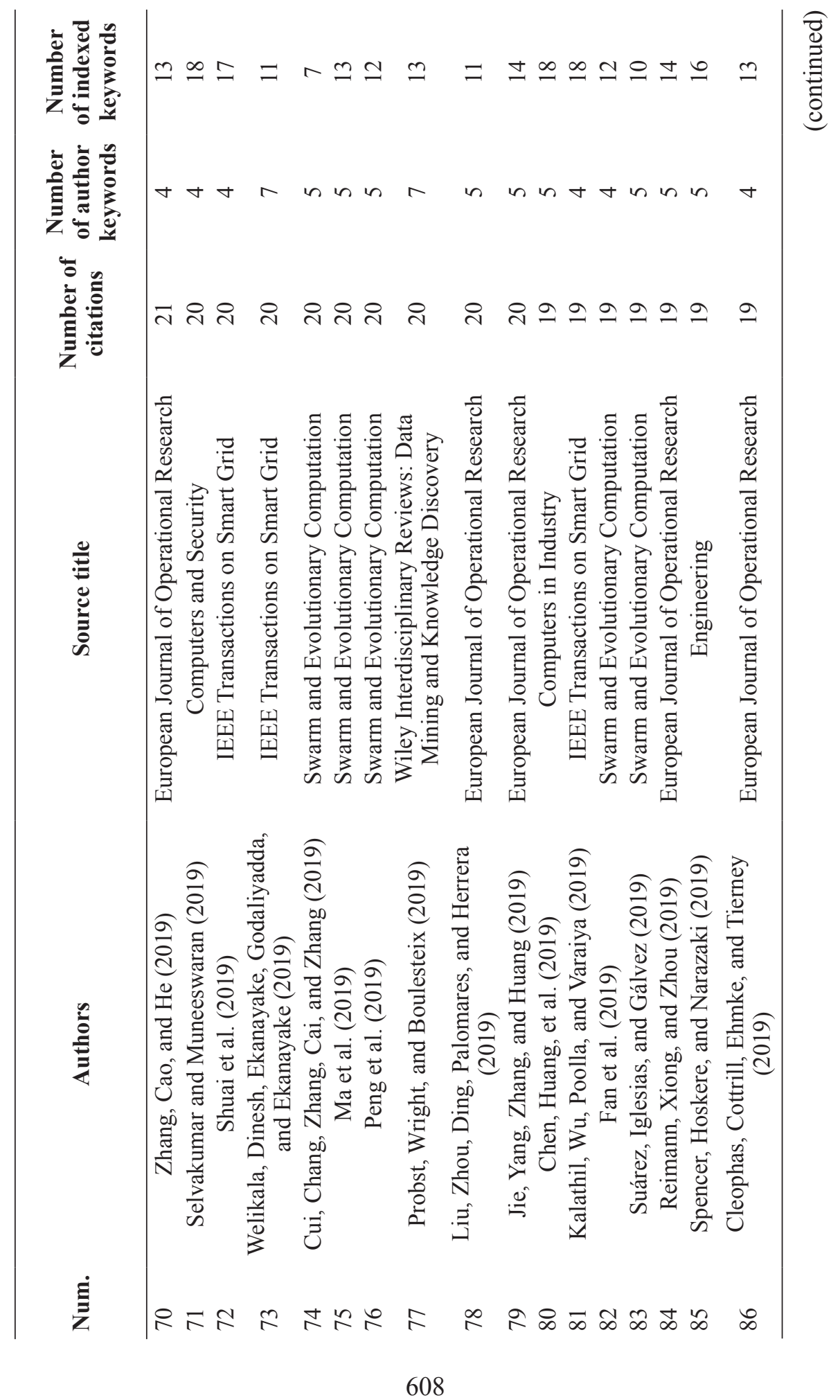




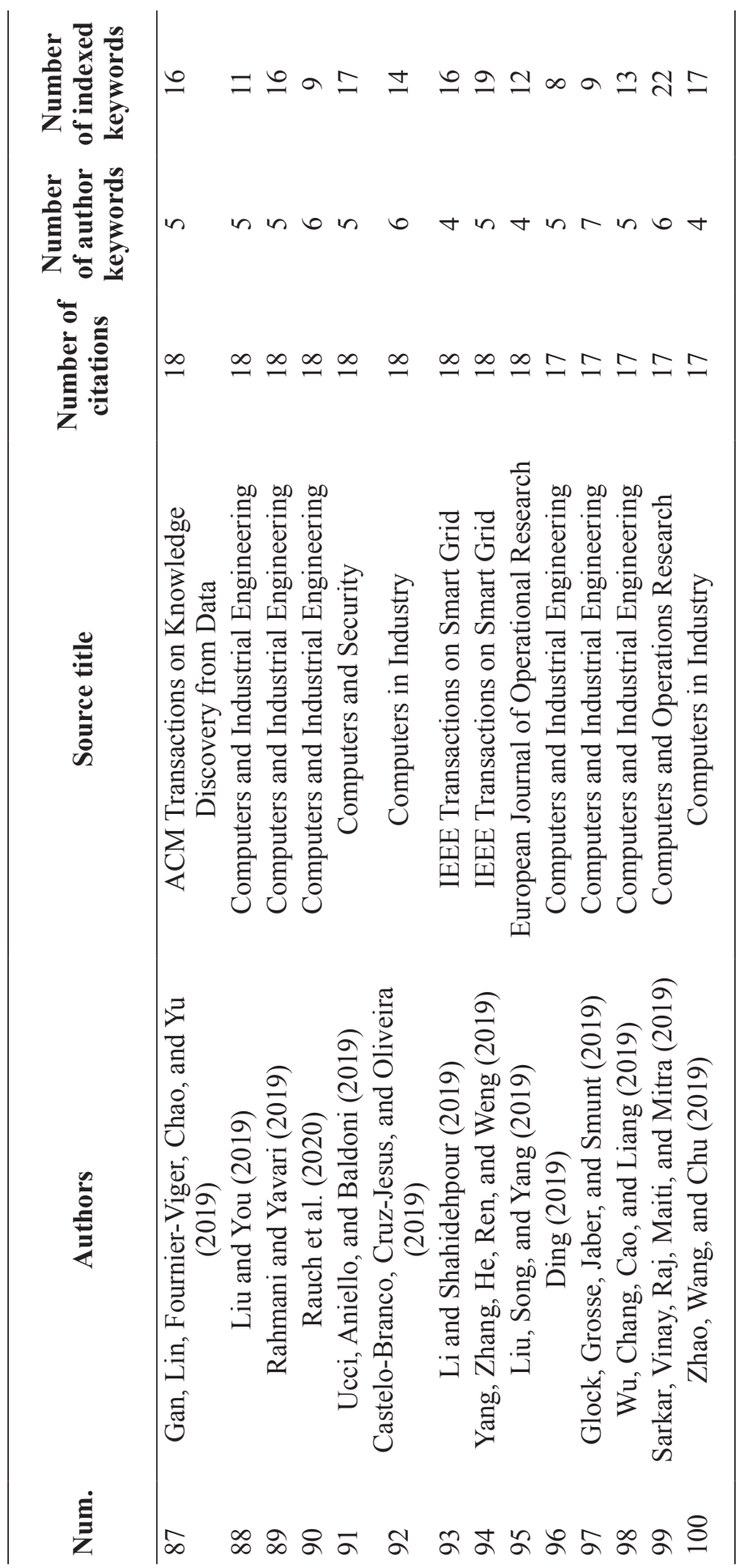


This study also intended to understand the characteristics of highly-cited articles in general computer science that had recently been published. First, the study looked at the prestigious journals that published the highly-cited articles. "IEEE Transactions on Smart Grid" was identified as the journal with the highest number of highly-cited articles in the dataset. It was also in the first rank of journals in the general computer science subject area based on 2018 CiteScore metrics. In 2018, the journal received a total citation of 10,830, and the number of citation increased to 14,292 in 2019 (this study took place at the time Scopus was yet to publish the 2019 CiteScore metrics; therefore, it used the estimation of data on 9 April 2020). "IEEE Transactions on Smart Grid" is available in Scopus database since 2010 and it has 3,236 indexed articles to date. The editor-in-chief of the journal is Claudio Cañizares from the University of Waterloo, Canada. Table 12 lists other journals that had a good number of highly-cited articles in the dataset.

\section{Table 12}

Journals of top 100 highly-cited articles

\begin{tabular}{lc}
\hline \multicolumn{1}{c}{ Journals } & Number of articles \\
\hline IEEE Transactions on Smart Grid & 31 \\
European Journal of Operational Research & 17 \\
Swarm and Evolutionary Computation & 13 \\
Computers and Industrial Engineering & 13 \\
Computers in Industry & 7 \\
ACM Computing Surveys & 5 \\
Computers and Education & 3 \\
Engineering & 3 \\
Wiley Interdisciplinary Reviews: Data Mining and & \\
Knowledge Discovery & 2 \\
Computers and Operations Research & 2 \\
Computers and Security & 2 \\
Human-centric Computing and Information Sciences & 1 \\
ACM Transactions on Knowledge Discovery from Data & 1 \\
\hline
\end{tabular}

This study further analysed the type of the top 100 highly-cited articles as listed in Table 11. The number of reviews and research articles in the dataset of highly-cited articles were 14 and 86, respectively. In terms of research funding, 68 studies specified their funding agencies. National Natural Science 
Foundation of China funded 42 studies of the highly-cited articles. Authors from China and the United States were the highest with 48 and 30, respectively from the total of 176 authors. Kang, Chongqing (Scopus ID 7402312938) was the highest contributor with four highly-cited articles published in "IEEE Transactions on Smart Grid". The h-index of this author was 42 with 370 published articles and 7,704 citations. His affiliation is Tsinghua University, Beijing, China. The characteristics of the top contributors might indicate vital information on the trend of publishing scientific studies. For example, Chinese authors and funding agencies were found to be the top contributors to the general computer science subject area. A benchmark study using studies published by Chinese researchers could be beneficial to the JICT editorial team so that the specific attributes of their studies can be identified and appropriate strategies can be taken to explore authors from China. Currently, JICT has received massive article submission of authors from India. Therefore, there could be an opportunity to broaden the current coverage of countries by promoting JICT to Chinese institutions.

\section{CONCLUSION}

This study aimed to address the issue of JICT's low citations through a scientometric analysis. The study has successfully identified the emerging topics and trends of scientific research in general computer science. The ten emerging topics in computer science as suggested by SciVal could be given priority by the editorial team in selecting article submissions for further peerreview process. Similarly, the top authors and indexed keywords might also be used as the scope of topic for article submissions in the near future. The characteristics of the highly-cited articles provide several new insights to the JICT editorial team on the potential of authors and scientific studies from China. Overall, the results of this study could be used by the JICT editorial team in selecting up-to-date studies for publication. It also helps the team to select the trending research topics and thus avoid obsolete studies that receive no attention from researchers in the discipline. Other journals in general computer science that suffer from the same issue might use the findings of this study to improve their performance and impact of the scientific studies that they publish.

\section{ACKNOWLEDGEMENT}

The authors thank Universiti Utara Malaysia for funding this study under the APIQ Special Grant Scheme (S/O Code: 13967), and Research and Innovation 
Management Centre, Universiti Utara Malaysia for the administration of this study.

\section{REFERENCES}

Abdel-Baset, M., Chang, V., \& Gamal,A. (2019). Evaluation of the green supply chain management practices: Anovel neutrosophic approach. Computers in Industry, 108, 210-220. doi:10.1016/j.compind.2019.02.013

Abdel-Baset, M., Chang, V., Gamal, A., \& Smarandache, F. (2019). An integrated neutrosophic ANP and VIKOR method for achieving sustainable supplier selection: A case study in importing field. Computers in Industry, 106, 94-110. doi:10.1016/j.compind.2018.12.017

Awidi, I. T., \& Paynter, M. (2019). The impact of a flipped classroom approach on student learning experience. Computers and Education, 128, 269283. doi:10.1016/j.compedu.2018.09.013

Bélanger, V., Ruiz, A., \& Soriano, P. (2019). Recent optimization models and trends in location, relocation, and dispatching of emergency medical vehicles. European Journal of Operational Research, 272(1), 1-23. doi:10.1016/j.ejor.2018.02.055

Boysen, N., de Koster, R., \& Weidinger, F. (2019). Warehousing in the e-commerce era: A survey. European Journal of Operational Research, 277(2), 396-411. doi:10.1016/j.ejor.2018.08.023

Buyya, R., Srirama, S. N., Casale, G., Calheiros, R., Simmhan, Y., Varghese, B., . . . Shen, H. (2019). A manifesto for future generation cloud computing: Research directions for the next decade. ACM Computing Surveys, 51(5). doi:10.1145/3241737

Castelo-Branco, I., Cruz-Jesus, F., \& Oliveira, T. (2019). Assessing Industry 4.0 readinessinmanufacturing: Evidence for the EuropeanUnion. Computers in Industry, 107, 22-32. doi:10.1016/j.compind.2019.01.007

Chen, K., Chen, K., Wang, Q., He, Z., Hu, J., \& He, J. (2019). Short-term load forecasting with deep residual networks. IEEE Transactions on Smart Grid, 10(4), 3943-3952. doi:10.1109/TSG.2018.2844307

Chen, R., Huang, X., Yang, L., Xu, X., Zhang, X., \& Zhang, Y. (2019). Intelligent fault diagnosis method of planetary gearboxes based on convolution neural network and discrete wavelet transform. Computers in Industry, 106, 48-59. doi:10.1016/j.compind.2018.11.003

Chukwusa, E., Verne, J., Polato, G., Taylor, R., J Higginson, I., \& Gao, W. (2019). Urban and rural differences in geographical accessibility to inpatient palliative and end-of-life (PEoLC) facilities and place of death: A national population-based study in England, UK. International Journal of Health Geographics, 18(1). doi:10.1186/s12942-0190172-1 
Cleophas, C., Cottrill, C., Ehmke, J. F., \& Tierney, K. (2019). Collaborative urban transportation: Recent advances in theory and practice. European Journal of Operational Research, 273(3), 801-816. doi:10.1016/j. ejor.2018.04.037

Cole, J., \& Cole, S. (1971). Measuring the quality of sociological research: Problems in the use of the "Science Citation Index". The American Sociologist, 23-29.

Cui, Z., Chang, Y., Zhang, J., Cai, X., \& Zhang, W. (2019). Improved NSGAIII with selection-and-elimination operator. Swarm and Evolutionary Computation, 49, 23-33. doi:10.1016/j.swevo.2019.05.011

De Giovanni, P., Karray, S., \& Martín-Herrán, G. (2019). Vendor management inventory with consignment contracts and the benefits of cooperative advertising. European Journal of Operational Research, 272(2), 465480. doi:10.1016/j.ejor.2018.06.031

Dehghanpour, K., Wang, Z., Wang, J., Yuan, Y., \& Bu, F. (2019). A survey on state estimation techniques and challenges in smart distribution systems. IEEE Transactions on Smart Grid, 10(2), 2312-2322. doi:10.1109/ TSG.2018.2870600

Del Ser, J., Osaba, E., Molina, D., Yang, X. S., Salcedo-Sanz, S., Camacho, D., ... Herrera, F. (2019). Bio-inspired computation: Where we stand and what's next. Swarm and Evolutionary Computation, 48, 220-250. doi:10.1016/j.swevo.2019.04.008

Deng, R., Benckendorff, P., \& Gannaway, D. (2019). Progress and new directions for teaching and learning in MOOCs. Computers and Education, 129, 48-60. doi:10.1016/j.compedu.2018.10.019

Diaz, M., Ferrer, M. A., Impedovo, D., Malik, M. I., Pirlo, G., \& Plamondon, R. (2019). A perspective analysis of handwritten signature technology. ACM Computing Surveys, 51(6). doi:10.1145/3274658

Ding, S. (2019). A novel discrete grey multivariable model and its application in forecasting the output value of China's high-tech industries. Computers and Industrial Engineering, 127, 749-760. doi:10.1016/j. cie.2018.11.016

Dizdarević, J., Carpio, F., Jukan, A., \& Masip-Bruin, X. (2019). A survey of communication protocols for internet of things and related challenges of fog and cloud computing integration. ACM Computing Surveys, 51(6). doi: $10.1145 / 3292674$

Elsevier. (2020). Topic prominence in science. Retrieved from https://www. elsevier.com/solutions/scival/releases/topic-prominence-in-science

Fan, Z., Li, W., Cai, X., Li, H., Wei, C., Zhang, Q., . . . Goodman, E. (2019). Push and pull search for solving constrained multi-objective optimization problems. Swarm and Evolutionary Computation, 44, 665-679. doi:10.1016/j.swevo.2018.08.017 
Fantini, P., Pinzone, M., \& Taisch, M. (2020). Placing the operator at the centre of Industry 4.0 design: Modelling and assessing human activities within cyber-physical systems. Computers and Industrial Engineering, 139. doi:10.1016/j.cie.2018.01.025

Fu, C., Chang, W., Xue, M., \& Yang, S. (2019). Multiple criteria group decision making with belief distributions and distributed preference relations. European Journal of Operational Research, 273(2), 623-633. doi:10.1016/j.ejor.2018.08.012

Gan, W., Lin, J. C. W., Fournier-Viger, P., Chao, H. C., \& Yu, P. S. (2019). A survey of parallel sequential pattern mining. ACM Transactions on Knowledge Discovery from Data, 13(3). doi:10.1145/3314107

Glock, C. H., Grosse, E. H., Jaber, M. Y., \& Smunt, T. L. (2019). Applications of learning curves in production and operations management: A systematic literature review. Computers and Industrial Engineering, 131, 422-441. doi:10.1016/j.cie.2018.10.030

Gupta, S., \& Deep, K. (2019). A novel random walk grey wolf optimizer. Swarm and Evolutionary Computation, 44, 101-112. doi:10.1016/j. swevo.2018.01.001

Hassan, H., Nasir, M. H. M., Khairudin, N., \& Adon, I. (2017). Factors influencing cloud computing adoption in small and medium enterprises. Journal of Information and Communication Technology, 16(1), 21-41.

Hazra, R., Singh, M., Goyal, P., Adhikari, B., \& Mukherjee, A. (2019). The rise and rise of interdisciplinary research: Understanding the interaction dynamics of three major fields - Physics, mathematics and computer science. Vol. 11853 LNCS. Lecture Notes in Computer Science (including subseries Lecture Notes in Artificial Intelligence and Lecture Notes in Bioinformatics) (pp. 71-77).

He, Q., Chen, B., Pei, J., Qiu, B., Mitra, P., \& Giles, L. (2009, November). Detecting topic evolution in scientific literature: How can citations help? In Proceedings of the 18th ACM International Conference on Information and Knowledge Management, Hong Kong (pp. 957-966).

He, Q., Wang, N., Yang, Z., He, Z., \& Jiang, B. (2019). Competitive collection under channel inconvenience in closed-loop supply chain. European Journal of Operational Research, 275(1), 155-166. doi:10.1016/j. ejor.2018.11.034

Hiermann, G., Hartl, R. F., Puchinger, J., \& Vidal, T. (2019). Routing a mix of conventional, plug-in hybrid, and electric vehicles. European Journal of Operational Research, 272(1), 235-248. doi:10.1016/j. ejor.2018.06.025

Holzinger, A., Langs, G., Denk, H., Zatloukal, K., \& Müller, H. (2019). Causability and explainability of artificial intelligence in medicine. Wiley Interdisciplinary Reviews: Data Mining and Knowledge Discovery, 9(4). doi:10.1002/widm.1312 
Huang, W., Zhang, N., Yang, J., Wang, Y., \& Kang, C. (2019). Optimal configuration planning of multi-energy systems considering distributed renewable energy. IEEE Transactions on Smart Grid, 10(2), 1452-1464. doi:10.1109/TSG.2017.2767860

Huber, J. E., \& Kolar, J. W. (2019). Applicability of solid-state transformers in today's and future distribution grids. IEEE Transactions on Smart Grid, 10(1), 317-326. doi:10.1109/TSG.2017.2738610

Hussain, A., Hashim, N. L., Nordin, N., \& Tahir, H. M. (2013). A metricbased evaluation model for applications on mobile phones. Journal of Information and Communication Technology, 12(1), 55-71.

Ivanov, D. (2019). Disruption tails and revival policies: A simulation analysis of supply chain design and production-ordering systems in the recovery and post-disruption periods. Computers and Industrial Engineering, 127, 558-570. doi:10.1016/j.cie.2018.10.043

Jain, M., Singh, V., \& Rani, A. (2019). A novel nature-inspired algorithm for optimization: Squirrel search algorithm. Swarm and Evolutionary Computation, 44, 148-175. doi:10.1016/j.swevo.2018.02.013

Jie, W., Yang, J., Zhang, M., \& Huang, Y. (2019). The two-echelon capacitated electric vehicle routing problem with battery swapping stations: Formulationandefficientmethodology.European JournalofOperational Research, 272(3), 879-904. doi:10.1016/j.ejor.2018.07.002

Jnr, B. A., Majid, M. A., \& Romli, A. (2018). An empirical study on predictors of green sustainable software practices in Malaysian electronic industries. Journal of Information and Communication Technology, 17(2), 347-391.

Kalathil, D., Wu, C., Poolla, K., \& Varaiya, P. (2019). The sharing economy for the electricity storage. IEEE Transactions on Smart Grid, 10(1), 556-567. doi:10.1109/TSG.2017.2748519

Kong, W., Dong, Z. Y., Jia, Y., Hill, D. J., Xu, Y., \& Zhang, Y. (2019). Short-term residential load forecasting based on LSTM recurrent neural network. IEEE Transactions on Smart Grid, 10(1), 841-851. doi:10.1109/ TSG.2017.2753802

Krauskopf, E. (2018). An analysis of discontinued journals by Scopus. Scientometrics, 116(3), 1805-1815. doi:10.1007/s11192-018-2808-5

Li, H., Deb, K., Zhang, Q., Suganthan, P. N., \& Chen, L. (2019). Comparison between MOEA/D and NSGA-III on a set of many and multi-objective benchmark problems with challenging difficulties. Swarm and Evolutionary Computation, 46, 104-117. doi:10.1016/j. swevo.2019.02.003

Li, M., \& Chen, Y. (2020). Wide-Area robust sliding mode controller for power systems with false data injection attacks. IEEE Transactions on Smart Grid, 11(2), 922-930. doi:10.1109/TSG.2019.2913691 
Li, P., Ji, H., Wang, C., Zhao, J., Song, G., Ding, F., \& Wu, J. (2019). Optimal operation of soft open points in active distribution networks under three-phase unbalanced conditions. IEEE Transactions on Smart Grid, 10(1), 380-391. doi:10.1109/TSG.2017.2739999

Li, S., Li, L., Li, Z., Chen, X., Fernando, T., Iu, H. H. C., . . Liu, X. (2019). Event-trigger heterogeneous nonlinear filter for wide-area measurement systems in power grid. IEEE Transactions on Smart Grid, 10(3), 27522764. doi:10.1109/TSG.2018.2810224

Li, Y., He, L., Liu, F., Li, C., Cao, Y., \& Shahidehpour, M. (2019). Flexible voltage control strategy considering distributed energy storages for DC distribution network. IEEE Transactions on Smart Grid, 10(1), 163172. doi:10.1109/TSG.2017.2734166

Li, Z., \& Shahidehpour, M. (2019). Small-signal modeling and stability analysis of hybrid AC/DC microgrids. IEEE Transactions on Smart Grid, 10(2), 2080-2095. doi:10.1109/TSG.2017.2788042

Liang, G., Weller, S. R., Luo, F., Zhao, J., \& Dong, Z. Y. (2019). Distributed blockchain-based data protection framework for modern power systems against cyber attacks. IEEE Transactions on Smart Grid, 10(3), 31623173. doi:10.1109/TSG.2018.2819663

Liu, B., Zhou, Q., Ding, R. X., Palomares, I., \& Herrera, F. (2019). Largescale group decision making model based on social network analysis: Trust relationship-based conflict detection and elimination. European Journal of Operational Research, 275(2), 737-754. doi:10.1016/j. ejor.2018.11.075

Liu, H. H., Song, Y. Y., \& Yang, G. L. (2019). Cross-efficiency evaluation in data envelopment analysis based on prospect theory. European Journal of Operational Research, 273(1), 364-375. doi:10.1016/j. ejor.2018.07.046

Liu, P., \& You, X. (2019). Bidirectional projection measure of linguistic neutrosophic numbers and their application to multi-criteria group decision making. Computers and Industrial Engineering, 128, 447457. doi:10.1016/j.cie.2018.12.052

Liu, S., Wang, Y., Yang, X., Lei, B., Liu, L., Li, S. X., . . Wang, T. (2019). Deep learning in medical ultrasound analysis: A review. Engineering, 5(2), 261-275. doi:10.1016/j.eng.2018.11.020

Long, H. V., Ali, M., Son, L. H., Khan, M., \& Tu, D. N. (2019). A novel approach for fuzzy clustering based on neutrosophic association matrix. Computers and Industrial Engineering, 127, 687-697. doi:10.1016/j. cie.2018.11.007

Ma, H., Shen, S., Yu, M., Yang, Z., Fei, M., \& Zhou, H. (2019). Multipopulation techniques in nature inspired optimization algorithms: A comprehensive survey. Swarm and Evolutionary Computation, 44, 365-387. doi:10.1016/j.swevo.2018.04.011 
Manavalan, E., \& Jayakrishna, K. (2019). A review of Internet of Things (IoT) embedded sustainable supply chain for industry 4.0 requirements. Computers and Industrial Engineering, 127, 925-953. doi:10.1016/j. cie.2018.11.030

Mocanu, E., Mocanu, D. C., Nguyen, P. H., Liotta, A., Webber, M. E., Gibescu, M., \& Slootweg, J. G. (2019). On-line building energy optimization using deep reinforcement learning. IEEE Transactions on Smart Grid, 10(4), 3698-3708. doi:10.1109/TSG.2018.2834219

Modak, N. M., \& Kelle, P. (2019). Managing a dual-channel supply chain under price and delivery-time dependent stochastic demand. European Journal of Operational Research, 272(1), 147-161. doi:10.1016/j. ejor.2018.05.067

Moed, H. F., \& Van Leeuwen, T. N. (1995). Improving the accuracy of institute for scientific information's journal impact factors. Journal of the American Society for Information Science, 46(6), 461-467. doi:10.1002/ (SICI)1097-4571(199507)46:6<461::AID-ASI5>3.0.CO;2-G

Mohammadi, A., Mehrtash, M., \& Kargarian, A. (2019). Diagonal quadratic approximation for decentralized collaborative TSO+DSO optimal power flow. IEEE Transactions on Smart Grid, 10(3), 2358-2370. doi:10.1109/TSG.2018.2796034

Morstyn, T., Teytelboym, A., \& McCulloch, M. D. (2019). Bilateral contract networks for peer-to-peer energy trading. IEEE Transactions on Smart Grid, 10(2), 2026-2035. doi:10.1109/TSG.2017.2786668

Opara, K. R., \& Arabas, J. (2019). Differential evolution: A survey of theoretical analyses. Swarm and Evolutionary Computation, 44, 546558. doi:10.1016/j.swevo.2018.06.010

Osaba, E., Yang, X. S., Fister, I., Jr., Del Ser, J., Lopez-Garcia, P., \& VazquezPardavila, A. J. (2019). A discrete and improved bat algorithm for solving a medical goods distribution problem with pharmacological waste collection. Swarm and Evolutionary Computation, 44, 273-286. doi:10.1016/j.swevo.2018.04.001

Pamucar, D., Chatterjee, K., \& Zavadskas, E. K. (2019). Assessment of third-party logistics provider using multi-criteria decision-making approach based on interval rough numbers. Computers and Industrial Engineering, 127, 383-407. doi:10.1016/j.cie.2018.10.023

Papari, B., Edrington, C. S., Bhattacharya, I., \& Radman, G. (2019). Effective energy management of hybrid AC-DC microgrids with storage devices. IEEE Transactions on Smart Grid, 10(1), 193-203. doi:10.1109/ TSG.2017.2736789

Pechlaner, H., Zehrer, A., Matzler, K., \& Abfalter, D. (2004). A ranking of international tourism and hospitality journals. Journal of Travel Research, 42(4), 328-332. doi:10.1177/0047287504263026 
Peng, K., Pan, Q. K., Gao, L., Li, X., Das, S., \& Zhang, B. (2019). A multistart variable neighbourhood descent algorithm for hybrid flowshop rescheduling. Swarm and Evolutionary Computation, 45, 92-112. doi:10.1016/j.swevo.2019.01.002

Probst, P., Wright, M. N., \& Boulesteix, A. L. (2019). Hyperparameters and tuning strategies for random forest. Wiley Interdisciplinary Reviews: Data Mining and Knowledge Discovery, 9(3). doi:10.1002/widm.1301

Qasim, M. (2017). Sustainability and wellbeing: A scientometric and bibliometric review of the literature. Journal of Economic Surveys, 31(4), 1035-1061. doi:10.1111/joes.12183

Rahmani, K., \& Yavari, M. (2019). Pricing policies for a dual-channel green supply chain under demand disruptions. Computers and Industrial Engineering, 127, 493-510. doi:10.1016/j.cie.2018.10.039

Rauch, E., Linder, C., \& Dallasega, P. (2020). Anthropocentric perspective of production before and within Industry 4.0. Computers and Industrial Engineering, 139. doi:10.1016/j.cie.2019.01.018

Reimann, M., Xiong, Y., \& Zhou, Y. (2019). Managing a closed-loop supply chain with process innovation for remanufacturing. European Journal of Operational Research, 276(2), 510-518. doi:10.1016/j. ejor.2019.01.028

Sahoo, S., \& Mishra, S. (2019). A distributed finite-time secondary average voltage regulation and current sharing controller for DC microgrids. IEEE Transactions on Smart Grid, 10(1), 282-292. doi:10.1109/ TSG.2017.2737938

Salih, M. M., Zaidan, B. B., Zaidan, A. A., \& Ahmed, M. A. (2019). Survey on fuzzy TOPSIS state-of-the-art between 2007 and 2017. Computers and Operations Research, 104, 207-227. doi:10.1016/j.cor.2018.12.019

Sarkar, S., Vinay, S., Raj, R., Maiti, J., \& Mitra, P. (2019). Application of optimized machine learning techniques for prediction of occupational accidents. Computers and Operations Research, 106, 210-224. doi:10.1016/j.cor.2018.02.021

Scherer, R., Siddiq, F., \& Tondeur, J. (2019). The technology acceptance model (TAM): A meta-analytic structural equation modeling approach to explaining teachers' adoption of digital technology in education. Computers and Education, 128, 13-35. doi:10.1016/j. compedu.2018.09.009

Scopus Support Center. (2019). What is field-weighted citation impact (FWCI)? Retrieved from https://service.elsevier.com/app/answers/ detail/a_id/14894/supporthub/scopus/

Scopus Support Center. (2020). How do author / indexed keywords work? Retrieved from https://service.elsevier.com/app/answers/detail/a id/21730/supporthub/scopus/ 
Seiti, H., \& Hafezalkotob, A. (2019). Developing the R-TOPSIS methodology for risk-based preventive maintenance planning: A case study in rolling mill company. Computers and Industrial Engineering, 128, 622-636. doi:10.1016/j.cie.2019.01.012

Selvakumar, B., \& Muneeswaran, K. (2019). Firefly algorithm based feature selection for network intrusion detection. Computers and Security, 81, 148-155. doi:10.1016/j.cose.2018.11.005

Shehab, M., Khader, A. T., \& Laouchedi, M. (2018). A hybrid method based on Cuckoo search algorithm for global optimization problems. Journal of Information and Communication Technology, 17(3), 469-491.

Shen, Y., Yao, W., Wen, J., He, H., \& Jiang, L. (2019). Resilient wide-area damping control using GrHDP to tolerate communication failures. IEEE Transactions on Smart Grid, 10(3), 2547-2557. doi:10.1109/ TSG.2018.2803822

Shuai, H., Fang, J., Ai, X., Tang, Y., Wen, J., \& He, H. (2019). Stochastic optimization of economic dispatch for microgrid based on approximate dynamic programming. IEEE Transactions on Smart Grid, 10(3), 2440-2452. doi:10.1109/TSG.2018.2798039

Spencer, B. F., Jr., Hoskere, V., \& Narazaki, Y. (2019). Advances in computer vision-based civil infrastructure inspection and monitoring. Engineering, 5(2), 199-222. doi:10.1016/j.eng.2018.11.030

Suárez, P., Iglesias, A., \& Gálvez, A. (2019). Make robots be bats: Specializing robotic swarms to the bat algorithm. Swarm and Evolutionary Computation, 44, 113-129. doi:10.1016/j.swevo.2018.01.005

Ucci, D., Aniello, L., \& Baldoni, R. (2019). Survey of machine learning techniques for malware analysis. Computers and Security, 81, 123-147. doi:10.1016/j.cose.2018.11.001

Wang, J., Gu, X., Liu, W., Sangaiah, A. K., \& Kim, H. J. (2019). An empower hamilton loop based data collection algorithm with mobile agent for WSNs. Human-centric Computing and Information Sciences, 9(1). doi:10.1186/s13673-019-0179-4

Wang, L., Xue, X., Zhao, Z., \& Wang, Z. (2018). The impacts of transportation infrastructure on sustainable development: Emerging trends and challenges. International Journal of Environmental Research and Public Health, 15(6). doi:10.3390/ijerph15061172

Wang, X., \& Blaabjerg, F. (2019). Harmonic stability in power electronic-based power systems: Concept, modeling, and analysis. IEEE Transactions on Smart Grid, 10(3), 2858-2870. doi:10.1109/TSG.2018.2812712

Wang, Y., Chen, Q., Hong, T., \& Kang, C. (2019). Review of smart meter data analytics: Applications, methodologies, and challenges. IEEE Transactions on Smart Grid, 10(3), 3125-3148. doi:10.1109/ TSG.2018.2818167 
Wang, Y., Zhang, N., Kang, C., Kirschen, D. S., Yang, J., \& Xia, Q. (2019). Standardized matrix modeling of multiple energy systems. IEEE Transactions on Smart Grid, 10(1), 257-270. doi:10.1109/ TSG.2017.2737662

Wang, Y., Zhang, N., Tan, Y., Hong, T., Kirschen, D. S., \& Kang, C. (2019). Combining probabilistic load forecasts. IEEE Transactions on Smart Grid, 10(4), 3664-3674. doi:10.1109/TSG.2018.2833869

Welikala, S., Dinesh, C., Ekanayake, M. P. B., Godaliyadda, R. I., \& Ekanayake, J. (2019). Incorporating appliance usage patterns for non-intrusive load monitoring and load forecasting. IEEE Transactions on Smart Grid, 10(1), 448-461. doi:10.1109/TSG.2017.2743760

Wu, G., Mallipeddi, R., \& Suganthan, P. N. (2019). Ensemble strategies for population-based optimization algorithms - A survey. Swarm and Evolutionary Computation, 44, 695-711. doi:10.1016/j. swevo.2018.08.015

Wu, J., Chang, J., Cao, Q., \& Liang, C. (2019). A trust propagation and collaborative filtering based method for incomplete information in social network group decision making with type-2 linguistic trust. Computers and Industrial Engineering, 127, 853-864. doi:10.1016/j. cie.2018.11.020

Wu, X., \& Liao, H. (2019). A consensus-based probabilistic linguistic gained and lost dominance score method. European Journal of Operational Research, 272(3), 1017-1027. doi:10.1016/j.ejor.2018.07.044

Xu, Q., Zhang, C., Wen, C., \& Wang, P. (2019). A novel vomposite nonlinear controller for stabilization of constant power load in DC microgrid. IEEE Transactions on Smart Grid, 10(1), 752-761. doi:10.1109/ TSG.2017.2751755 rfseq1

Yan, H., Zhou, X., Zhang, H., Yang, F., \& Wu, Z. G. (2019). A novel sliding mode estimation for microgrid control with communication time delays. IEEE Transactions on Smart Grid, 10(2), 1509-1520. doi:10.1109/ TSG.2017.2771493

Yan, Q., Zhang, B., \& Kezunovic, M. (2019). Optimized operational cost reduction for an EV charging station integrated with battery energy storage and PV generation. IEEE Transactions on Smart Grid, 10(2), 2096-2106. doi:10.1109/TSG.2017.2788440

Yan, R., Tang, J., Liu, X., Shan, D., \& Li, X. (2011). Citation count prediction: Learning to estimate future citations for literature. In Proceedings of the 20th ACM International Conference on Information and Knowledge Management, Glasgow, Scotland, UK (pp. 1247-1252).

Yang, L., Ye, Z. S., Lee, C. G., Yang, S. F., \& Peng, R. (2019). A two-phase preventive maintenance policy considering imperfect repair and postponed replacement. European Journal of Operational Research, 274(3), 966-977. doi:10.1016/j.ejor.2018.10.049 
Yang, X., Zhang, Y., He, H., Ren, S., \& Weng, G. (2019). Real-time demand side management for a microgrid considering uncertainties. IEEE Transactions on Smart Grid, 10(3), 3401-3414. doi:10.1109/ TSG.2018.2825388

Yu, J. J. Q., Hou, Y., Lam, A. Y. S., \& Li, V. O. K. (2019). Intelligent fault detection scheme for microgrids with wavelet-based deep neural networks. IEEE Transactions on Smart Grid, 10(2), 1694-1703. doi:10.1109/TSG.2017.2776310

Yusuf-Asaju, A. W., Dahalin, Z. M., \& Ta'a, A. (2018). Framework for modelling mobile network quality of experience through big data analytics approach. Journal of Information and Communication Technology, 17(1), 79-113.

Zakir Hossain, M. D., Sohel, F., Shiratuddin, M. F., \& Laga, H. (2019). A comprehensive survey of deep learning for image captioning. $A C M$ Computing Surveys, 51(6). doi:10.1145/3295748

Zeng, G. Q., Xie, X. Q., Chen, M. R., \& Weng, J. (2019). Adaptive population extremal optimization-based PID neural network for multivariable nonlinear control systems. Swarm and Evolutionary Computation, 44, 320-334. doi:10.1016/j.swevo.2018.04.008

Zeraati, M., Hamedani Golshan, M. E., \& Guerrero, J. M. (2019). A consensusbased cooperative control of PEV battery and PV active power curtailment for voltage regulation in distribution networks. IEEE Transactions on Smart Grid, 10(1), 670-680. doi:10.1109/TSG.2017.2749623

Zhang, A. H., Sun, H., Yan, G. L., Han, Y., Zhao, Q. Q., \& Wang, X. J. (2019). Chinmedomics: A powerful approach integrating metabolomics with serum pharmacochemistry to evaluate the efficacy of traditional Chinese medicine. Engineering, 5(1), 60-68. doi:10.1016/j.eng.2018.11.008

Zhang, B., Dehghanian, P., \& Kezunovic, M. (2019). Optimal allocation of PV generation and battery storage for enhanced resilience. IEEE Transactions on Smart Grid, 10(1), 535-545. doi:10.1109/TSG.2017.2747136

Zhang, B., Zhang, S., \& Li, W. (2019). Bearing performance degradation assessment using long short-term memory recurrent network. Computers in Industry, 106, 14-29. doi:10.1016/j.compind.2018.12.016

Zhang, H., Dong, Y., Chiclana, F., \& Yu, S. (2019). Consensus efficiency in group decision making: A comprehensive comparative study and its optimal design. European Journal of Operational Research, 275(2), 580-598. doi:10.1016/j.ejor.2018.11.052

Zhang, H., Kou, G., \& Peng, Y. (2019). Soft consensus cost models for group decision making and economic interpretations. European Journal of Operational Research, 277(3), 964-980. doi:10.1016/j. ejor.2019.03.009

Zhang, J., Cao, Q., \& He, X. (2019). Contract and product quality in platform selling. European Journal of Operational Research, 272(3), 928-944. doi:10.1016/j.ejor.2018.07.023 
Zhang, K., Zhan, J., Wu, W., \& Alcantud, J. C. R. (2019). Fuzzy $\beta$-covering based (I,T)-fuzzy rough set models and applications to multi-attribute decision-making. Computers and Industrial Engineering, 128, 605621. doi:10.1016/j.cie.2019.01.004

Zhang, S., Yao, L., Sun, A., \& Tay, Y. (2019). Deep learning based recommender system: A survey and new perspectives. ACM Computing Surveys, 52(1). doi: $10.1145 / 3285029$

Zhao, D., Wang, T., \& Chu, F. (2019). Deep convolutional neural network based planet bearing fault classification. Computers in Industry, 107, 59-66. doi:10.1016/j.compind.2019.02.001

Zhao, J., \& Mili, L. (2019). Robust unscented Kalman filter for power system dynamic state estimation with unknown noise statistics. IEEE Transactions on Smart Grid, 10(2), 1215-1224. doi:10.1109/ TSG.2017.2761452 